DOI: 10.12731/2658-6649-2019-11-5-118-122

УДК 616.33

\title{
ОЦЕНКА \\ ПРОЛИФЕРАТИВНО-АПОПТОТИЧЕСКОГО СТАТУСА ЭПИТЕЛИОЦИТОВ СЛИЗИСТОЙ ОБОЛОЧКИ ЖЕЛУДКА У ПАЦИЕНТОВ С АТРОФИЧЕСКИМ ГАСТРИТОМ
}

Перетятько О.В., Цуканов В.В., Пуликов А.С.

Изучение показателей клеточного обновления эпителиоцитов слизистой оболочки желудка при атрофическом гастрите может оптимизировать диагностические и терапевтические подходы, учитывая, что данная форма гастрита является предраковым заболеванием. Методом иммуногистохимии были определены маркеры пролиферащии и апоптоза Ki-67, PCNA, p53 и bcl-2 в гастробиоптатах больных в возрасте 45-60 лет неатрофическим и атрофическим гастритом. В результате исследования был определен пролиферативно-апоптотический статус эпителиочитов слизистой оболочки желудка, который позволяет сделать вывод о снижении репаративных прочессов.

Ключевые слова: апоптоз; пролиферация; атрофический гастрит; неатрофический гастрит; эпителиочиты слизистой оболочки желудка.

\section{ASSESSMENT \\ OF THE PROLIFERATIVE-APOPTOTIC STATUS OF EPITHELIAL CELLS OF THE GASTRIC MUCOSA AMONG PATIENTS WITH ATROPHIC GASTRITIS}

Peretyat'ko O.V., Tsukanov V.V., Pulikov A.S.

The study of indicators of cellular renewal of epithelial cells of the gastric mucosa in atrophic gastritis can optimize diagnostic and therapeutic approaches, given that this form of gastritis is a precancerous disease. Markers of proliferation and apoptosis of Ki-67, PCNA, p53 and bcl-2 in gastrobioptates of patients aged 45-60 years with non-atrophic and atrophic gastritis were determined by immunohistochemistry. As a result of the study, the prolifera- 
tive-apoptotic status of epithelial cells of the gastric mucosa was determined, which leads to a conclusion about the reduction of reparative processes.

Keywords: apoptosis; proliferation; atrophic gastritis; non-atrophic gastritis; epithelial cells of gastric mucosa.

\section{Введение}

Согласно современным представлениям, атрофический гастрит является предраковым заболеванием, которое может приводить к развитию рака желудка [1]. В основе патогенеза атрофического гастрита лежат аутоиммунные реакции, ассоциация с В12-зависимой анемией, недостаточной выработке соляной кислоты, гормональными нарушениями, ассоциации с бактерией Helicobacter Pylori и т.д. Все это обуславливает необходимость уточнения патоморфологических особенностей при данной патологии. Изучение особенностей морфогенеза рака желудка с оценкой показателей клеточного обновления поможет оптимизировать диагностические подходы для разработки обоснованной терапии $[2,3]$. Клеточное обновление происходит постоянно в течение жизни за счет процессов пролиферации и апоптоза, в виду чего поддерживаются необходимые физиологические функции клеток и тканей и реализуются процессы регенерации при повреждении [4]. Таким образом, целью данного исследования явилась оценка пролиферативно-апоптотического потенциала клеток эпителиоцитов слизистой оболочки желудка у больных с атрофическим гастритом в оценке прогноза развития заболевания.

\section{Материалы и методы исследования}

Материалом исследования служили гастробиоптаты слизистой оболочки желудка. Все пациенты, участвующие в научном исследовании были проинформированы о наборе биоматериала, что подтверждалось подписанным информированным согласием. Все исследуемые пациенты находились в возрастном диапазоне 45-60 лет и не делились на группы по полу. Всего было проанализировано 54 гастробиоптата. В 1 исследуемую группу (неатрофический гастрит) вошел 21 пациент, во 2 группу (атрофический гастрит) вошли 33 пациента. Обработка биоматериала производилась по стандартным гистологическим методикам с заливкой в парафин. Парафиновые срезы толщиной около 5 мкм подвергались этапу демаскировки антигенов, обрабатывались разведенными антителами маркеров пролиферации и апоптоза Ki-67 (Clone: MIB-1, 1:25), bcl-2 (Clone: 124, 1:50), p53 (Clone: DO-7, 1:25) и PCNA (Clone: PC10, 1:200) (Дако, Дания) с последующей обработкой системой визуализации EnVision Detection Systems Peroxidase/DAB (Дако, Дания) в соот- 
ветствии с протоколом производителя. Докраска гистологических структур осуществлялась гематоксилином. Препараты оценивались на микроскопе «Olympus CX 41» (Япония). Процент количества клеток и ядер с признаками пролиферации и апоптоза вычислялся с использованием стереометрической сетки Г.Г. Автандилова, вмонтированной в окуляр микроскопа. Статистический анализ данных производился с использованием программной версии «Statistica for Windows», 6.0 (StatSoft Inc., США).

\section{Результаты исследования}

В группе неатрофического гастрита наблюдалось статистическое преобладание пролиферативных функций клеток над апоптозом, как по показателю Ki67, так и по PCNA. (8,0 и 9,0\% соответственно) $(\mathrm{P}<0.05)$. Данные показатели были также достоверно выше относительно группы пациентов с атрофическом гастритом (P<0.05). Показатели апоптоза, выражающиеся в экспрессии белков p53 и bcl-2 были примерно на одном и том же уровне во всех исследуемых группах, однако в случае атрофического гастрита индекс Ki67/bcl2 и PCNA/bcl2 составил 1,07 и 1,5 соответственно, что статистически было ниже аналогичных показателей у пациентов с неатрофическим гастритом $(\mathrm{P}<0.05)$.

\section{Обсуждение}

Увеличение пролиферативной активности относительно процессов апоптоза в группе неатрофического гастрита свидетельствует об активных компенсаторных процессах, в то время как при атрофическом гастрите процессы пролиферации замедляются, что связано преимущественно с атрофическими явлениями в эпителиоцитах слизистой оболочки желудка. Практически одинаковое количество апоптотического белка р53 и PCNA в случае атрофического гастрита высокой степени активности свидетельствует о запуске репаративных систем в S-фазе клеточного цикла.

\section{Заключение}

При хроническом атрофическом гастрите оценка пролиферативно-апоптотического отношения свидетельствует о снижении репаративных процессов эпителиоцитов слизистой оболочки желудка.

Информация о конфликте интересов. У авторов нет конфликта интересов.

Информация о спонсорстве. Исследование не имело спонсорской поддержки. 


\section{Список литературы}

1. Correa P. Gastric cancer: overview. Gastroenterol Clin North Am. 2013. 42(2), pp. 211-217.

2. Цуканов В.В., Амельчугова О.С., Каспаров Э.В., Буторин Н.Н., Васютин А.В., Тонких Ю.Л., Третьякова О.В. Роль эрадикации Helicobacterpylori в профилактике рака желудка. Терапевт. арх. 2014. 86(8), pp. 124-127.

3. Petersson F., Borch K., Franzén L.E. Prevalence of subtypes of intestinal metaplasia in the general population and in patients with autoimmune chronic atrophic gastritis. Scand J Gastroenterol. 2002. 37(3), pp. 262-266.

4. Shamma A., Doki Y., Shiozaki H., Tsujinaka T., Inoue M., Yano M., Kimura Y., Yamamoto M., Monden M. Effect of cyclin D1 and associated proteins on proliferation of esophageal squamous cell carcinoma. Int J Oncol. 1998. Sep.13(3), pp. 455-60.

\section{References}

1. Correa P. Gastric cancer: overview. Gastroenterol Clin North Am. 2013. 42(2), pp. 211-217.

2. Cukanov V.V., Amel'chugova O.S., Kasparov E.V., Butorin N.N., Vasyutin A.V., Tonkih Yu.L., Tret'yakova O.V. Terapevt. arh., 2014, 86(8), pp. 124-127.

3. Petersson F., Borch K., Franzén L.E. Prevalence of subtypes of intestinal metaplasia in the general population and in patients with autoimmune chronic atrophic gastritis. Scand J Gastroenterol. 2002. 37(3), pp. 262-266.

4. Shamma A., Doki Y., Shiozaki H., Tsujinaka T., Inoue M., Yano M., Kimura Y., Yamamoto M., Monden M. Effect of cyclin D1 and associated proteins on proliferation of esophageal squamous cell carcinoma. Int J Oncol. 1998. Sep.13(3), pp. 455-60.

\section{ДАННЫЕ ОБ АВТОРАХ}

Перетятько Ольга Викторовна, научный сотрудник, к.б.н.

Научно-исследовательский институт медициских проблем Севера ФИЦ КНЦ СО РАН

ул. Партизана Железняка, 32, Красноярск, 660022, Российская Федерачия

peretyatkoolga@mail.ru

Цуканов Владислав Владимирович, заведующий отделением, д.м.н., профессор

Научно-исследовательский институт медичинских проблем Севера ФИЦ КНЦ СО РАН 
ул. Партизана Железняка, 32, Красноярск, 660022, Российская Федерачия gastro@impn.ru

Пуликов Анатолий Степанович, главный научный сотрудник, д.м.н., профессор

Научно-исследовательский институт медичинских проблем Севера ФИЦ КНЦ СО РАН

ул. Партизана Железняка, 32, Красноярск, 660022, Российская Федерачия

Pulik_off@mail.ru

DATA ABOUT THE AUTHORS

Peretyat'ko Olga Viktorovna, research fellow

Scientific Research Institute for Medical Problems of the North FRC KSC SB RAS

3g, Partizan Zheleznyak str., Krasnoyarsk, 660022, Russian Federation peretyatkoolga@mail.ru

ORCID: 0000-0003-1142-3933

Tsukanov Vladislav Vladimirovich, head of department, professor

Scientific Research Institute for Medical Problems of the North FRC KSC SB RAS

3g, Partizan Zheleznyak str., Krasnoyarsk, 660022, Russian Federation gastro@impn.ru

ORCID: 0000-0002-9980-2294

Pulikov Anatoliy Stepanovich, chief researcher, professor

Scientific Research Institute for Medical Problems of the North FRC KSC SB RAS

3g, Partizan Zheleznyak str., Krasnoyarsk, 660022, Russian Federation Pulikoff@mail.ru

ORCID: 0000-0002-8751-5861 